\title{
AUTOMATION OF SCHEME PREPARATION AND BOQ CALCULATION FOR L\&T-ALUFORM
}

\author{
Nagi Reddy Sattigari \\ M. Tech Student, \\ BTCM Division \\ Department of Civil Engineering \\ Indian Institute of Technology Madras \\ Chennai - 600 036, India \\ Snreddy1980@gmail.com
}

\author{
Ashwin Mahalingam \\ Assistant Professor, \\ BTCM Division \\ Department of Civil Engineering \\ Indian Institute of Technology Madras \\ Chennai - 600 036, India \\ mash@iitm.ac.in
}

\author{
George Thomas \\ Chief Engineer Manager \\ FCCE, ECC Division \\ Larsen \& Toubro Limited \\ Manapakkam, PB No. 679 \\ Chennai-600089. India \\ gt@Intecc.com
}

\begin{abstract}
Aluminium Formwork System is a comparatively new technology in India. Generally, aluminium formwork consists of standard sized panels and custom sized panels. The total area of custom shaped formwork elements can be reduced by optimizing the allocation of standard-sized formwork elements. This can in turn lead to large savings in formwork costs and time for scheme preparations. An application to automate the optimization and scheme preparation for L\&T Aluminium Formwork was developed using Visual Basic 6.0. The application captures spatial details of a building element from an AutoCAD Drawing and uses an optimization algorithm to develop a formwork scheme as well as a Bill of Quantities. The application also takes into account the formwork elements available at site and optimizes their usage. The tool has been validated with four cases taken from two ongoing projects. The validation shows improvement in usage of standard sized formwork elements in the order of $10 \%$ to $13 \%$ for complex shapes and $1 \%$ to $2 \%$ for simple shapes.
\end{abstract}

\section{KEYWORDS}

Scheme Preparation, Aluminium Formwork, Bill of Quantities, Optimization

\section{GENERAL}

Formwork systems are the backbone of construction activity especially for high-rise buildings. According to the System Formwork Manual of L\&T ECCD, formwork systems constitute about $40 \%$ of the cost and $60 \%$ of the time for any construction activity.

Amongst the various alternatives currently available for mass housing construction, aluminium formwork not only satisfies the main criteria of speed, quality and economy, but also has other attributes such as safety, lightness of weight, fewer number of components, etc. This system has been in use in India for nearly a decade and has proved its worth on a number of recently constructed jobs.

Details of each and every formwork element are essential to build the formwork for any structure. These details are represented in a drawing known 
as the "Scheme Drawing". Thus far the scheme drawings for L\&T aluminium formwork - a category of Aluminium formwork patented by Larsen \& Toubro ECC Ltd - are mostly prepared manually. Generally, the formwork engineer works out the layout of formwork elements for a particular structure. Based on the formwork engineer's suggestions, the draftsman prepares the scheme drawing in AutoCAD and list outs the bill of quantities of the formwork elements used for that structure.

Aluminum formwork elements can be divided into two groups, one being standard size/shape elements and the other, custom size/shape elements. Generally, for any structure, formwork has both standard size/shape elements and custom size/shape elements. Standard-sized formwork elements are generally readily available, but the custom sized, shaped formwork elements have to be fabricated by order. One has to work out the shape and total number of the custom-sized panels required from the drawings well before the execution of the work. The special fabrication of custom-sized panels, their incorporation in the drawings and the preparation of a Bill of Quantities consume a lot of time and resources and increases cost.

Therefore it would be beneficial to reduce the total area of custom shaped formwork elements by allocating the standard-sized formwork elements in a systematic manner using the available software and optimization techniques. Manual planning methods are far less likely to yield optimal formwork schemes.

\section{LITERATURE REVIEW}

A number of researchers and investigators have studied the impact of various kinds of formwork systems and resources on critical matters such as project duration, project cost, productivity achieved, etc. Also a lot of work has been done related to the optimum utilization of space in setting up of site facilities - storage yards, labour colony, plants and major equipment like batching plant, tower cranes, concrete pumps etc. Studies have been made comparing the effectiveness and efficiencies of various formwork systems.

\subsection{Review of the Academic Literature on I.T. Applications for Formwork}

While disciplines such as structural analysis are reaping the benefits of computer implementation; temporary works design lags well behind. Some of the reasons given by temporary works designers are that their designs are very practical and depend largely on the designer's experience and engineering judgement (Taha and Price, 1991).

A package developed by Taha and Price (1991) produces design details, a schedule of quantities, a cost comparison between purchased and hired proprietary formwork, and a cost estimate.

A conceptual model for implementing the stiffness method in formwork design was also proposed by Taha and Price (1997). They assessed the use of existing software for solving the stiffness equations. This is used to develop the detailed formwork design program.

Huang, Chen and Sun (2004) employed computer process simulation techniques in their research for the study of different form reuse schemes to use gang forming systems in building construction.

Many researchers are developing IT applications for the use of formwork. At present, the research and development of IT applications for formwork are limited to a few areas of formwork such as the design of formwork, cost estimation, cost comparisons between different formwork systems and formwork labour productivity measurement tools [2]. Aluminium formwork is a comparatively new formwork system, and has not been the subject of automation research. In addition automation of formwork scheme preparation - the area of research that we plan to pursue - has not been adequately addressed in the existing research on IT applications for formwork systems.

\subsection{A Review of Tools Used in Practice}

DOKA has developed a software called "TiposDOKA Formwork Planning 5.0" for planning and design of Doka-formwork. Tipos is a planning and organization tool that helps to deal with a wide range of different tasks in connection with the planning and management of formwork [6].

PASCHAL has developed a software called "PASCHAL- PLAN light" for automated 
formwork design. The programme automatically creates a formwork design for given layout. By means of the default values the user can modify the formwork drawing according to his needs [7].

Despite the existence of these tools, there is little or no work done currently regarding the automation of scheme preparation for Aluminium formwork. Automating the scheme preparation and preparing the bill of quantities will definitely improve the labour and material productivity and efficiency of aluminium formwork systems.

\section{SCOPE OF THE PROJECT}

A Literature survey was done in the area of formwork, to discover the major areas of research and to discover gaps in current knowledge. From this survey, it was found that automated preparation of scheme drawings for an aluminium formwork (L\&T- AluForm) had not been dealt with earlier in the academic literature. Therefore this is picked as the area of research. The scheme drawings are preparing manually for L\&TAluForm. We first needed to analyse the current manual practices of scheme preparation and to develop the generalised methodology for scheme preparation of aluminium formwork. We then built up flowcharts/algorithms for the generalized methodologies. Finally we developed a software tool, by using Visual Basic 6.0, with reference to the above flow charts, to automate the process of scheme preparation for L\&T - AluForm, for:

- Scheme Preparation for Slabs / Floors and

- Calculation of Bill of Quantities

The outputs of the software tool are:

- An optimised formwork scheme based on the available resources in the inventory (or for the case of unlimited resources)

\section{SOFTWARE PLATFORM SELECTION}

Generally, structural drawings are prepared in the CAD environment. Therefore the development environment must be able to interact with AutoCAD, to read/write to the AutoCAD drawings. The developing environment must also interact with MS Excel to read and write the bill of the quantities for the formwork. (Most of the construction engineers in India use MS Excel to store their data)

Potential software development environments were, C, C++, C\#, Visual C++, Visual Basic, Auto LISP, Visual LISP, FORTRAN, JAVA, .NET and so on. However, only a few of these development environments met our requirements. They were Visual Basic, Visual $\mathrm{C}++$, and Visual Basic Applications for AutoCAD. Out of these environments, we chose Visual Basic 6.0 as the environment to develop this project. The software tool to automate scheme preparation was then developed in this environment.

\section{SYSTEM DESCRIPTION}

The software tool requests the user to open an AutoCAD file. The program also requests the user to pick up all corner points of the slab, for which the user wants to prepare the scheme drawing. The program captures the coordinates of the picked points and keeps it in memory up to end of the program, and uses these coordinates for logical decision making.

Standard size/shaped formwork elements are created in AutoCAD and converted into AutoCAD blocks. The Visual Basic program can insert single or multiple copies of these blocks into any AutoCAD drawing.

The Visual Basic program considers all functional and logical requirements of the formwork systems to get an optimized solution, and decides the block profile and where each block has to be inserted in the drawing. While inserting the standard sized/shaped formwork elements into the AutoCAD drawing, the software tool counts the quantities of all formwork elements and displays it as a summary bill of quantities at the end. Screen shot of the application is shown in fig 1.

\subsection{Functional Relations between Different Formwork Elements}

The following are the some of the functional relations between the formwork elements that were used in the algorithm.

i. Two types of standard sized formwork elements are considered. These are 
rectangular elements of 450x900 mm and 450x1100 mm dimensions respectively.

ii. Aluspan beams (Aluminium beams that span an entire column of formwork elements) are required at the end of each column of formwork elements because these are the structural elements, which transfer the load from the slab panels to the props.

iii. For the entire width of a column between aluspan beams, the same type of slab panels (same length) should be placed.

iv. Adjustable slab panels are placed at the end of the each column (same length as other slab panels in the column). If the gap available is less the $450 \mathrm{~mm}$ and greater than $200 \mathrm{~mm}$ then adjustable slab panels are recommended. If the gap is less than $200 \mathrm{~mm}$, then custom sized slab panels are recommended.

v. A slab corner (100 mm width and $125 \mathrm{~mm}$ depth) should be placed along all walls (in the inside face of the room). The slab corner is the connector between the wall formwork and the slab formwork.

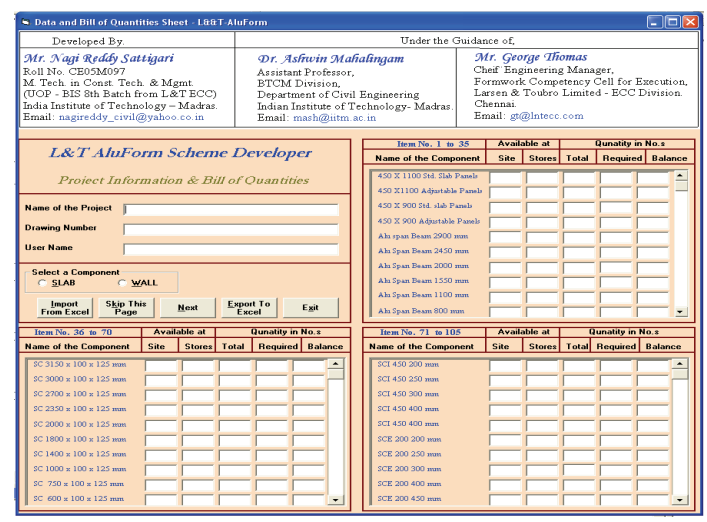

Figure 1 Screen Shot of Data \& Bill of Quantities Sheet of L\&T AluForm Scheme Developer

\subsection{Optimization Technique}

In several industrial applications one is required to allocate a set of rectangular items into larger rectangular standardized stock units by minimizing the waste. In wood or glass industries, rectangular components have to be cut from large sheets of material. In warehousing contexts, goods have to be placed on shelves. In newspaper paging, articles and advertisements have to be arranged in pages. In these applications, the standardized stock units are rectangles, and a common objective function is to pack all the requested items into the minimum number of units: the resulting optimization problems are known in the literature as "twodimensional bin packing problems (2BP)". In other contexts, such as paper or cloth industries, we have instead a single standardized unit (a roll of material), and the objective is to obtain the items by using the minimum roll length. These problems are then referred to as "two-dimensional strip packing problems (2SP)" [3].

In our case, the requirement is to allocate a set of smaller rectangular items into a larger shape (it may be of any size and shape). This is nearly similar to the "two dimensional bin packing problems (2BP)". However our problem has the following significant deviations from 2BP.

i. The larger shape may be of any size and shape in case of this project, whereas it is a standard rectangular shape in $2 \mathrm{BP}$.

ii. For our purposes, the set of smaller rectangular items must fulfil functional relationships between them when placed, whereas in $2 \mathrm{BP}$, when there are no such constraints, one can orient/rotate and accommodate them at any location in the larger rectangular standard shape.

iii. In our problem, multiple copies of the set of smaller rectangular items have to be accommodated. A-priori, we do not know how many pieces we need. In 2BP, only one set of the given rectangular items have to be accommodated in the larger rectangular standard shape.

iv. The area of the uncovered portion of the large shape should be as small as possible for our project i.e. one has to use as many copies of the set of smaller rectangular items as possible to minimize the unoccupied area of the large shape. In contrast, in $2 \mathrm{BP}$, the given set of the 
smaller rectangular items (only one set, no copies) have to be accommodated in the minimum area of the given larger rectangular standard shape.

From the above mentioned deviations, one can conclude that the optimization techniques used for two dimensional bin packing problems cannot be directly used, but have to be modified. Blending different techniques, a trial and error method with some modifications is suggested.

In this technique, the program calculates the number of columns of standard sized formwork elements for different formwork types and sizes i.e. no of columns it can place, if it places only $450 \times 1100 \mathrm{~mm}$ slab panels or if it places only $450 \times 900 \mathrm{~mm}$ slab panels. Then it calculates the end gap by arranging different combinations of 450x1100 and 450x 900 slab panels, and finds out the combination(s) which give the minimum end gap.

The combination, which gives the minimum end gap, is the optimized solution for the shape. In case of irregular rectangular shapes, the program divides that shape into small virtual rectangular shapes and finds out the combination for each virtual rectangular shape. The flowchart for this technique is shown in Fig 2.

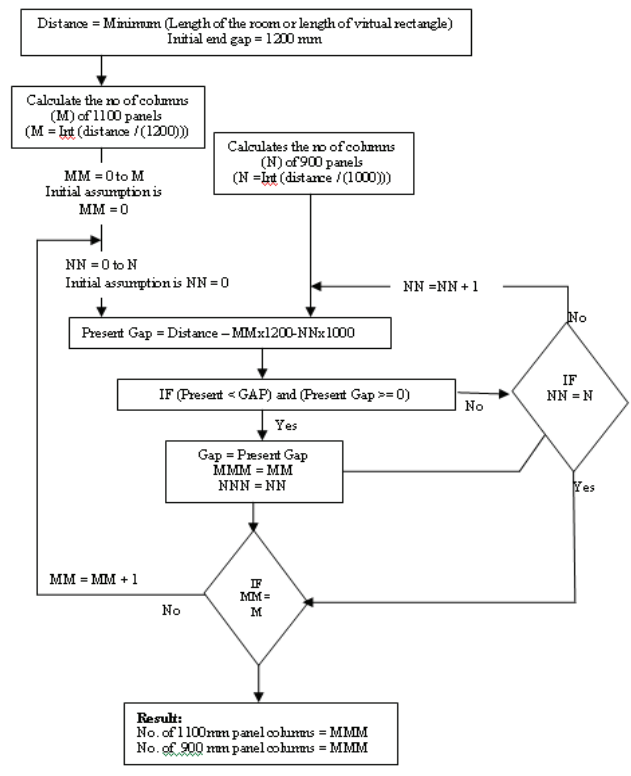

Figure 2 Flow Chart of Optimization Technique
The work procedure for slab formwork and its optimization flowchart are explained with the help of a schematic diagram for a simple slab given in Fig. 3. The algorithm first divides the entire area into rectangular sections. Each section is analyzed separately.

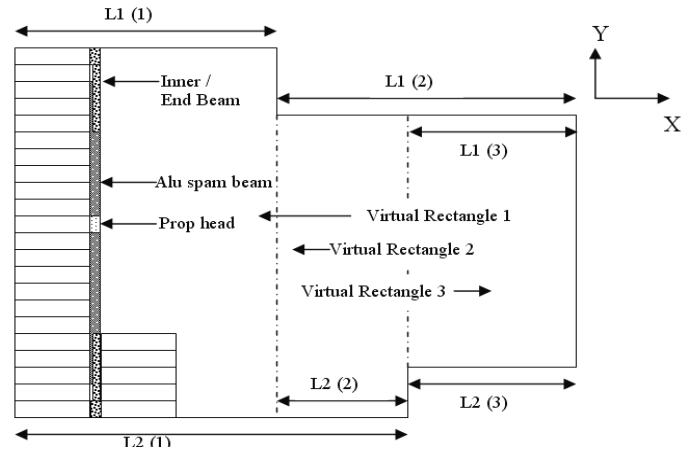

Figure 3 Slab Formwork with L\&T-AluForm

An example of a rectangular section is shown in Fig 4 and is titled "Virtual Rectangle 1". For this example section it is possible to place 3 distinct $450 \times 900$ panels or 2 distinct $450 \times 1100$ slab panels. The algorithm calculates the end gap by first assuming that 450x1100 panels are not used and by placing as many columns of $450 \times 900$ panels as possible. Then the algorithm increases the number of columns of $450 \times 1100$ panels by 1 and calculates the end gap. This iteration continues by decreasing the number of $450 \times 900$ panel columns and increasing the number of $450 \times 1100$ panel columns until there are no columns of 450x900 panels. A Schematic diagram for the optimised solution for slab formwork is shown in Fig 4.

The algorithm calculates the end gap for all possible combinations of the 1100 and 900 slab panels. The combination(s), which will minimize the end gap is/are the optimized solution(s). For virtual rectangle 1 of Fig. 4, the minimum end gap corresponds to the placement of 3 distinct columns of 450x900 panel forms. This is the optimized formwork scheme for this example.

\section{VALIDATION}

The developed software was validated with four cases taken from two ongoing projects. Scheme drawings prepared by the software tool were 
compared with manually prepared scheme drawings. In particular we compared the area occupied by standard sized panels in the scheme drawings generated both manually and with the software. Scheme Drawing Prepared manually for Case Study 2 is shown in fig 5. Scheme Drawing Prepared by the Software Tool for Case Study 2 is shown in fig 6.

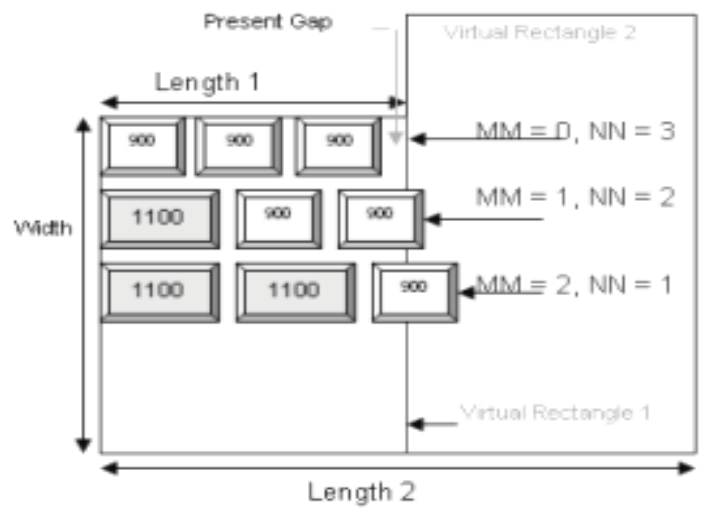

Figure 4 Schematic Diagram to Find an Optimized Solution for Slab Formwork

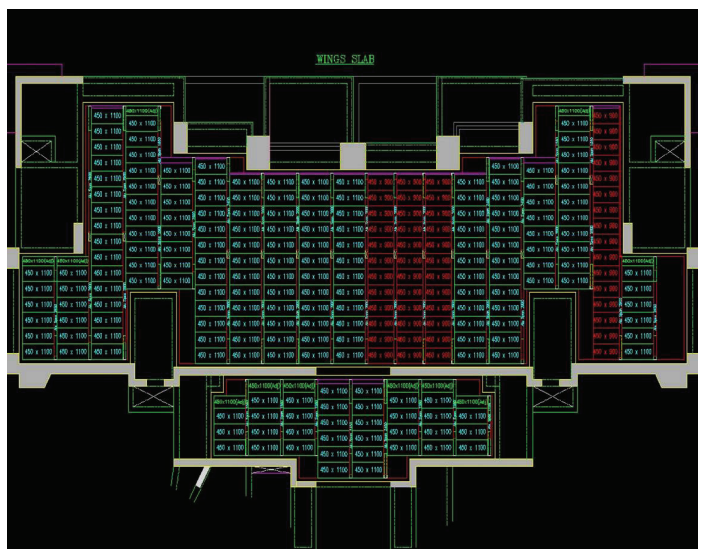

Figure 5 Scheme Drawing Prepared Manually for Case Study 2

A summary of the validation experiment is presented in table 1 . The software tool was seen to fill $69.04 \%$ to $76.13 \%$ (an average of $71.66 \%$ ) of the total formwork area by placing standard sized slab panels. In contrast, in the manual method that range was $63.46 \%$ to $69.63 \%$ and the average is $67.35 \%$. Therefore by using the software tool, the usage of standard sized slab panels increased by $4.31 \%$ (on average) with respect to the total area of formwork, and by $6.40 \%$ (on average) in comparison to the area of standard sized formwork elements in manual scheme preparation.

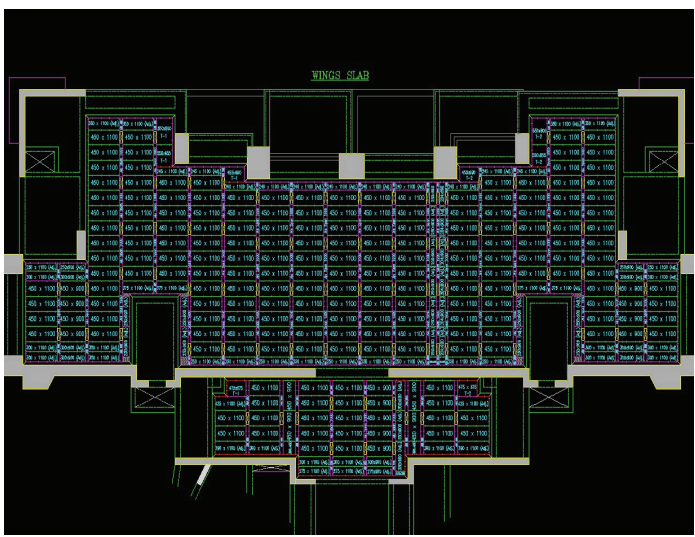

Figure 6 Scheme Drawing Prepared by the Software Tool for Case Study 2

Table 1 Summary of Validation Results

\begin{tabular}{|c|c|c|c|c|c|c|c|}
\hline & Formwork & \multicolumn{2}{|c|}{$\begin{array}{c}\text { Area of Std } \\
\text { panels }\end{array}$} & \multicolumn{2}{|c|}{$\begin{array}{c}\text { Percentage } \\
\text { area of } \\
\text { Standard } \\
\text { panels } \\
\end{array}$} & \multicolumn{2}{|c|}{ Savings } \\
\hline Case & $\begin{array}{l}\text { AREA } \\
(\mathrm{Sqm})\end{array}$ & $\begin{array}{c}\text { Software } \\
\text { Tool }\end{array}$ & Manual & $\begin{array}{l}\text { Soft- } \\
\text { ware } \\
\text { Tool } \\
(\%)\end{array}$ & $\begin{array}{c}\text { Manu } \\
\text { al } \\
(\%)\end{array}$ & $\begin{array}{l}\text { w r t } \\
\text { (FW } \\
\text { area) }\end{array}$ & $\begin{array}{c}\text { w r t } \\
\text { ( man- } \\
\text { ual) }\end{array}$ \\
\hline 1 & 109.196 & 76.320 & 69.300 & 69.89 & 63.46 & $6.43 \%$ & $10.13 \%$ \\
\hline 2 & 152.493 & 116.100 & 102.420 & 76.13 & 67.16 & $8.97 \%$ & $13.36 \%$ \\
\hline 3 & 144.047 & 101.655 & 100.305 & 70.57 & 69.63 & $0.94 \%$ & $1.35 \%$ \\
\hline 4 & 127.878 & 88.290 & 87.345 & 69.04 & 68.30 & $0.74 \%$ & $1.08 \%$ \\
\hline Total & 533.614 & 382.365 & 359.370 & & & & \\
\hline \multicolumn{4}{|c|}{ Average } & $71.66 \%$ & $\begin{array}{c}67.35 \\
\%\end{array}$ & $4.31 \%$ & $6.40 \%$ \\
\hline
\end{tabular}

\section{DISCUSSION OF THE ADVANTAGES OF THE SOFTWARE APPLICATION}

\section{i. Greater usage of standard sized formwork elements}

Area occupied by standard sized formwork elements is increased by around $13 \%$ for complex shapes and is around $1 \%$ for simple rectangular shapes. This means that usage of standard size formwork elements is increased 
by $13 \%$ for complex shapes and $1 \%$ for simple rectangular shapes.

\section{ii. Improvement in readability of scheme drawing}

Scheme drawing developed by the software tool is more easily readable and implementable because, the orientation of standard size slab panels are same for entire shape making very easy to read and understand the drawing, where as in general in manual drawings the orientation is in both ( $\mathrm{x}$, y) directions in one shape making the users refer very frequently to the drawings while executing the job. $450 \mathrm{~mm} \times 1100 \mathrm{~mm}$ panels are showed in green colour and $450 \mathrm{~mm} \times 900 \mathrm{~mm}$ panels are showed in red colour in scheme drawings developed by the software tool, where as all slab panels are in one colour in manually developed drawings.

\section{iii. Reduction in fabrication Costs}

Generally, each custom panel is unique because of its size and shape, so each custom panel needs to be designed separately and needs to represent the design detail in the fabrication drawings. Therefore time consumption for the fabrication of a custom panel is more than the time consumption for a standard panel. Semi Skilled technicians are sufficient to fabricate standard panels whereas skilled technicians are essential for the fabrication of custom panels. The software tool utilizes more number of standard sized formwork elements. Thus it will reduce the area for custom size/shaped formwork elements and consequently reduce fabrication costs.

\section{iv. Reduction of lead time between drawings received and execution}

The software tool can develop the scheme drawing for a given shape in a couple of minutes, whereas the manual method consumes more than one hour for the same drawing. Lead time between the drawing received to develop scheme drawings and drawings released to the site for execution will definitely reduce if one uses the software tool.

\section{v. Elimination of errors in BOQ Calculations}

The tool counts the formwork elements while inserting the standard panels in the given drawing. Therefore there is no likelihood for errors to be made in the calculation of the Bill of Quantities. In contrast, in manual methods, there is a larger scope for errors in the BOQ, because the user has to count each formwork element manually.

\section{vi. Reduction in effort required from the user}

User has to open a relevant drawing file and pick all the corner points of the slab/wall to develop the scheme drawing by the software tool. Software tool inserts/places standard panels and leaves areas for custom panels, which the user has to insert. In the case of manual method each and every element has to be placed by the user.

The software tool developed to automate the scheme preparation and BOQ calculation is more useful for complicated structures than simple structures. For simple shapes, it saves only in terms of time consumption but for complex shapes, it saves in terms of material reuse, time consumption and fabrication costs.

\section{CONCLUSIONS}

Selecting the right developing environment is the key to software development. We used Visual Basic 6.0 as a development environment to develop a software tool for "Automation of scheme preparation and BOQ calculation for L\&T AluForm". This tool has been named as the "L\&T AluForm Scheme Developer".

This tool to develop the scheme drawings for slabs, has been validated with four cases taken from two ongoing projects. We carried out some sensitivity analysis on our validation experiment and found that the improvement in the usage of standard sized formwork elements through using the software was of the order of $10 \%$ to $13 \%$ for complex shapes (cases $1 \& 2$ ) and only $1 \%$ to $2 \%$ for simple shapes (case $3 \& 4$ ). This indicates that the software is more useful for complex, nonrectangular shapes, where several scheme layouts are possible and arriving at an optimized layout is non-intuitive. 
The developed software - "L\&T AluForm Scheme Developer" - has the following advantages over the conventionally used manual method of scheme preparation for L\&T AluForm.

- Allocates more no. of standard size panels.

- Greatly improves readability of scheme drawings.

- Reduces fabrication costs / time for custom panels.

- Quickens scheme preparation.

- Automates BOQ calculations.

- Eliminates the need to employ high skills to produce scheme drawings.

- Reduces effort required from the user.

- Facilitates easy explanation/execution at site level.

\section{LIMITATIONS}

This software tool also has some limitations that are discussed below.

i. This tool has some geometric limitations, i.e. this tool works well for regular/irregular rectangular/square shapes but it cannot develop schemes for curved or inclined shapes

ii. Tool cannot allow the user to withdraw any point picked (as a part of the input) from an AutoCAD drawing.

iii. The current version of the program cannot automatically insert custom sized/shaped slab panels. The user will have to manually design and place custom shaped slab panels in the designated areas.

iv. We have used a trail and error algorithm to find the optimised solution. This algorithm can give very fast results for slabs of lengths of around $30 \mathrm{~m}$. However, for longer slabs, performance of the system with respect to time will decrease (processing time will increase). Perhaps a better algorithm can be developed.

\section{SCOPE FOR FUTHER DEVELOPEMENT}

An automated tool to develop the schemes for slab has been developed and has been shown to have practical benefits in terms of cost, time and effort savings. Future work could include developing tools to deal with walls with openings, columns, beams, sunken slabs, stair cases, and any other special structural elements of buildings. The L\&TAluForm scheme developer has some (above mentioned) limitations. Future work can overcome these limitations.

\section{REFERENCES}

[1] Huang, Rong-yau; Chen, Jeam-Jei; Sun, KuoShun (2004) "Planning gang formwork operations for building construction using simulations", Automation in Construction 13, pp 765-779.

[2] John Christian and Saif U. Mir (1988) “The use of expert systems and sensitivity analyses in formwork productivity and design", Computers \& Structures vol 30. No. 3, pp. 737-739.

[3] Lodi, Andrea; Martello, Silvano; Monaci, Michele (2002) "Two-dimensional Packing problems: A survey", European Journal of Operational Research 141pg. 241-252.

[4] Taha, J. H. M and Price, A. D. F. (1997) "Computer-aided formwork design: A detailed approach", Advances in Engineering Software 28 pp. 437- 454.

[5] Taha, J. H. M and Price, A. D. F. (1991) "Interactive Computer-Aided Formwork Design", Computers \& Structures vol 41. No. 6, pp. 1157-1167.

[6] DOKA website, Visited on 14th May 2007 $<$ http://www.doka.com/doka/en_global/servic es/formwork/tipos/module/index.php>

[7] PASCHAL website, last visited on $14^{\text {th }}$ May2007

$<$ http://www.steelengineers.com/catalog/more info.cfm/326> 